Response, part of a Special Feature on Law and Social-Ecological Resilience

\title{
Response to "Panarchy and the Law"
}

\author{
C. S. Holling ${ }^{1}$
}

Key Words: environmental law; panarchy theory

Panarchy Theory emphasizes four key features of change. One is the important role that diversity has during recovery after a disturbance, a role that can seed novelty, trigger invasions, or spawn innovation in the next sweep of the adaptive cycle. Another is the role of stability between disturbances, where the pattern unrolls predictably as the system grows, as it accumulates capital and ultimately reduces resilience. Still another is the role of an increasing likelihood of collapse across spatial/temporal scales, as collapse at one scale can propagate to larger/slower scales when those scales are vulnerable. And still another is the inhibition of that process of spreading (i.e., cross-scale collapse) as the memory of the bigger and slower scales sustain lower scale recovery. Some of those are unique to Panarchy; some shared with other theories.

It is these features that are the foundation for persistence, growth, and enrichment but also for crisis, collapse, and transformation to other regimes of behavior. How do those distinctive features relate to the Law?

Laws function to harmonize interactions between people. Laws therefore in part provide a base for assuring persistence of social and economic relationships among people. Those relationships range from the transient and local such as fads, through slower routines, still slower contracts and administrative rules, to, finally, laws and constitutions. Laws therefore represent relationships that cover large areas and long durations. They are persistent and embracing guides for and inhibitions to actions. In a system anticipating transformation, in a flip from one state to another, laws are truly of limited help, because the transformed system has unknown key variables and processes and unknown risks and opportunities emerge.

We now face changes of great social consequence that are unknown, beyond experience, and occurring on a global as well as regional stage. Past ones have included collapses of fisheries such as the cod (Gadus morhua) fisheries on the east coast of North America. Another example is the unanticipated death of lodgepole pine (Pinus contorta) from bark beetle (Dendroctonus ponderosae) attack that has spread over much of western North America. Still another is the dramatic $80 \%$ reduction of wading bird populations in the southern Everglades and the explosion of dying sea grass in south Florida Bay both of which cover large regional scales. These were all surprises at the time of their occurrence, whose causes now are clear. Some have since recovered naturally, some have triggered major remedial policies, and some have not recovered. They all have been caused by economic exploitations of resources that yielded economic advance or product at one scale while at the same time invisibly creating slow accumulation of spreading vulnerabilities: smaller and smaller loci for cod of restricted reproductive ages; spreading, even ages of lodgepole pine because of a hundred years plus of fire management and development; reduced diversity of species responsible for disturbing and consuming sea grasses, leading to spreading, single age stands of sea grasses.

All of these examples have led to remedial responses, from a moratorium on cod harvests, to salvaging dead lodgepole pine and limiting harvesting. The consequences are mixed because typically the bold experiments needed to clarify the unknown have not been implemented - their political costs to vested interests have concentrated action on the known, leading to very partial solutions with limited benefit.

The need therefore is for extensive and continuous monitoring over large scales in order to anticipate possible shifts in ecosystem and human behavior, while attempting to increase knowledge and introduce policies to maintain or enhance ecosystem attributes that sustain diversity. Not just a species focus, but an ecosystem, economic, and social focus. Not just local and regional responses, but continental and global ones. The record of attempting to do so indicates how tough that is. Witness the recent failures in achieving international accords for limiting greenhouse gas emissions. Not impossible but tough and long term. In the existing phase of financial and economic collapse and hesitant recovery, steps are even more difficult as a battle unrolls between powerful narrow vested interests and regulation on the one hand and less visible invention and innovation on the other.

All that can be done now is to focus on some fundamental developments that slow the worst problems and also dramatically explore several real options that are promising gambles. To me key ones concern energy. Shift from fossil fuels, enhance every possible renewable alternative across scales, substitute and implement smart electrical grids to distribute energy. Accelerate transformations for technologies to shift from fossil fuel to electric and use the resulting devices to store as well as use energy across regions, particularly electric. Conditions are not bad enough yet to do that with 
political ease, but experiments can be attempted whose key features need to cross scales. The internet, open source invention and collaboration, and crowd sourcing become critically important. Are there laws that further the flexibility? Aboriginal communities beginning to succeed in selfgovernance might give a start.

Spawn deliberative workshops to define and launch collaborative experiments. Talk, agitate, discuss, and collaborate. I doubt if new laws have much to contribute until consolidation of a new phase is underway. But local designs collaboratively initiated that cross scales have a central role.

Responses to this article can be read online at:

http://www.ecologyandsociety.org/issues/responses. $\mathrm{php} / 5402$ 